\title{
Selection of Best Combination of Nutrient Sources for Efficient Utilization of Nitrogen in Sandy Regosols
}

\author{
P. Premanandarajah \\ Department of Agric-Chemistry, Faculty of Agriculture, Eastern University Sri Lanka
}

*Corresponding Author: P. Premanandarajah, Department of Agric-chemistry, Faculty of Agriculture, Eastern University Sri Lanka

\begin{abstract}
A field trail and a laboratory test were conducted to study the effect of different types and rates of fertilizers on soil nitrogen content and nitrogen leaching in sandy regosols. There were twelve treatments and replicated four times. Organic manures such as Poultry Manure (PM), Rice Straw (RS) and Cattle Manure (CM) with control was tested at three levels of chemical fertilizers including control (unfertilized), recommended level (NPK) and half of the recommended level (1/2 NPK). PM and CM were applied at the rate of 10 tons/ha, but RS was at 5 tons/ha. Combining Poultry manure with chemical fertilizer treatments recorded higher soil nitrogen content and was followed by Cattle manure and chemical fertilizer combinations. But the treatments combining rice straw with chemical fertilizers recorded lowest value than sole chemical fertilizer and half the rate. Among the combinations of organic manures with chemical fertilizer combination with full dose of chemical fertilizer performed well than the half dose. The results revealed that Column contained organic manures with different rate of chemical fertilizer showed lower nitrate leaching than the columns without organic manure. There was no significant effect of type of organic manure on nitrate leaching. From these results it could be suggested that by combining organic manure with chemical fertilizer the nitrate leaching can be reduced.
\end{abstract}

Keywords: Chemical fertilizers, Nitrogen leaching, Organic Manures, Soil Nitrogen.

\section{INTRODUCTION}

Water resources in eastern coastal belt of Sri Lanka are polluted due to the heavy fertilization. As the region have predominately permeable soils with shallow water tables, which are more susceptible to leaching with high application rates making the groundwater potentially hazardous (Wijewardena, 2006). Because of the limited capacity of sandy regosols on building soil organic matter (SOM), lower capacity of water and nutrient retention farmers have to rely heavily on the use of external inputs on a seasonal basis.. Therefore different types of fertilizers are applied to achieve the peak of agricultural production.

In order to increase the ion and water retention capacity of sandy soil, organic manures are being applied thus can reduces the leaching loss of nutrient. FAO, (2000) stated that organic matter increases the retention of soil nutrients in a form available to the plant due to its capacity of exchange cations (CEC of humus ranges from $1-5 \mathrm{meq} / \mathrm{g}$ ). But the slow releasing ability of nutrient and lower crop production are the major problem in using organic manures.

But continues chemical fertilization also destroy the soil fertility and the use of excess fertilizer can result in a number of problems, such as nutrient loss, surface water and groundwater contamination, soil acidification or basification, reductions in useful microbial communities, and increased sensitivity to harmful insects (Chen, 2006).

Therefore by combining organic manures with chemical fertilizers soil nutrient and water retention capacity can be improved.

Against this backdrop, the present investigation was contemplated with the objectives of efficient utilization of nutrients by reducing leaching by combining different local organic manures with chemical fertilizers.

\section{Methodology}

Field and laboratory experiments were conducted to study the impact of different combination of 
organic manures and rate of chemical fertilizers on nitrate retention and leaching in sandy regosols. There were twelve treatments and replicated four times and laid on strip plot design. The treatments were 10 tons/ ha PM + NPK (T1), 10 tons / ha PM (T2), 10 tons / ha PM + 1/2 NPK (T3), 5 tons /ha RS + NPK (T4), 5 tons /ha RS (T5), 5 tons/ ha RS + 1/2 NPK (T6), NPK (T7), Control (Unfertilized) (T8), $1 / 2$ NPK (T9), 10 tons / ha CM + NPK (T10), 10 tons / ha CM ( T11), 10 tons / ha CM + 1/2 NPK (T12).

For field trial experimental plot was made with the size of $2 \mathrm{~m} \mathrm{X} 0.9 \mathrm{~m}$. A spacing of $0.5 \mathrm{~m}$ separated plots from each other and a space of $1 \mathrm{~m}$ wide separated the blocks from each other. Based on the treatment combinations the organic manure was incorporated with the soil uniformly to a depth of 10 $-15 \mathrm{~cm}$ a week prior to the planting. Seed onion bulbs were treated with fungicide and directly dibbled in plots consists of 10 rows, giving of total 80 plants per plot. All the agronomic practices were followed based on recommendation. Soil nitrogen content was estimated at harvest by using standard kjeldhal method (Wild et al., 1997).

For Laboratory experiment twelve leaching columns were filled with soil and organic manure mixture according to treatments. Same quantity of water was added at same flow rate to each column. Leachate was collected by using black-coated bottle. In every three weeks starting from three weeks after filling up of fertilizer mixture, ncollecting bottles were changed and the leachate was analyzed for its Nitrate nitrogen by spectrophotometer (Gupta, 1999) method.

\section{RESUltS AND DisCUSSION}

\section{Soil nitrogen content}

Among the treatments, combining Poultry manure with chemical fertilizer treatments recorded higher soil nitrogen content and was followed by Cattle manure and chemical fertilizer combinations. This may be due to higher nutrient content of poultry manure. This was supported by Amanullah et al. (2007) reported that the poultry manure occupied a place of pride as it is rich in nutrients than the other manures. But the treatments combining rice straw with chemical fertilizers recorded lowest value than sole chemical fertilizer and half the rate. This may be due to the wider $\mathrm{C}: \mathrm{N}$ ratio of straw. Ariyaretne, (2008) also supported that the incorporation of plant residue like paddy straw with high C: $\mathrm{N}$ ratio into the soil takes long duration for decomposition; therefore $\mathrm{N}$ is not available to the plants temporarily. Organic manure increases the water and nutrient retention of soils, thus preventing plant nutrient loss by leaching. Also higher nitrogen content and faster rate of decomposition of poultry manure may be the major reason for the higher availability of nitrogen in poultry manure treated soil. The findings were in agreement with by Ayeni (2008).

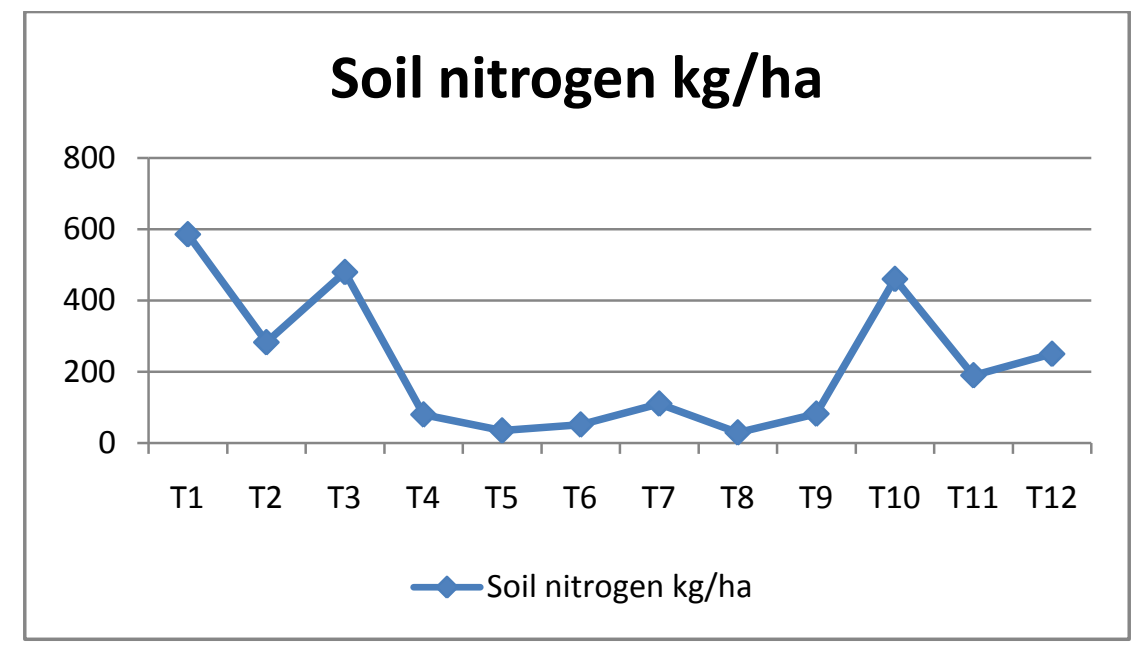

Figure 1. Effect of different treatments on soil nitrogen content

Among the combinations of organic manures with chemical fertilizer combination with full dose of chemical fertilizer performed well than the half dose. This may be due to higher availability of nutrients by the chemical fertilizer as the organic manures may take time to release nutrients and also rather than supplying nutrients that may increase the retention capacity of the soil. Addition of organic manures develops better soil physical properties which are very much important for nutrient retention. Addition of organic manures increased the soil moisture content strengthened the 
infiltration capacity and reduced leaching and erosion losses. Also Organic matter increases the retention of soil nutrients in a form available to the plant due to its nutrient retention capacity and the ability to release nutrient slowly (CEC of humus ranges from 1-5 meq/g) (FAO, 2000). Singh (2007) studied the effect of integrated nutrient management on soil quality changes over time and reported that the soil quality in terms of $\mathrm{CEC}, \mathrm{pH}, \mathrm{N}, \mathrm{P}, \mathrm{K}$, organic matter, soil texture, etc., were increased up to 58 per cent.

\section{Leachate nitrate}

The interaction of organic manures with chemical fertilizer was highly significant. Column contained organic manures with different rate of chemical fertilizer showed lower nitrate leaching than the columns without organic manure. It may be due to increased cation exchange capacity of those soils. FAO, (2000) stated that organic matter increases the retention of soil nutrients in a form available to the plant due to its capacity of exchange cations (CEC of humus ranges from 1-5 meq/g).

There was no significant effect of type of organic manure on nitrate leaching. From these results it could be suggested that by combining organic manure with chemical fertilizer the nitrate leaching can be reduced. Integrating nutrient management, including optimized $\mathrm{N}$ fertilizer input, as well as enhanced the soil organic matter content, should be considered to maintain soil fertility and productivity, minimize potential $\mathrm{N}$ losses and achieve sustainable development in greenhouse vegetable cropping systems (Tao et al., 2014).

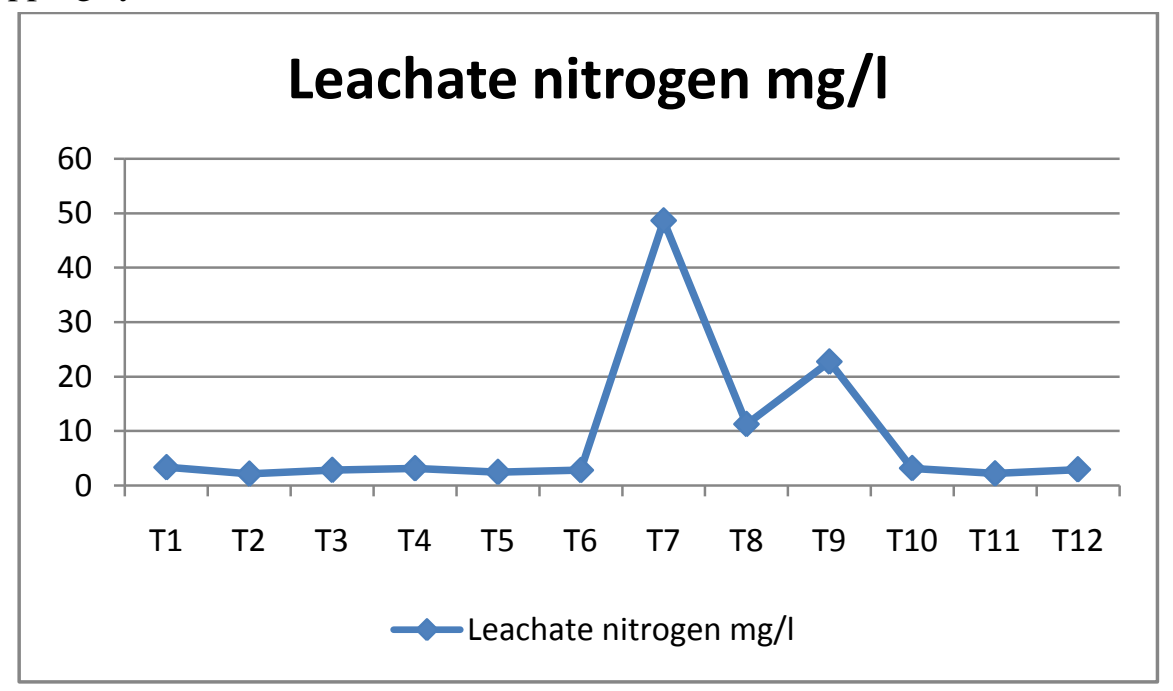

Figure 2. Effect of treatment combination on nitrate leaching

Figure 3 clearly indicated the correlation between soil nitrogen content and nitrate leaching. By applying organic manure the soil nutrient retention can be improved and thereby leaching loss can be controlled.

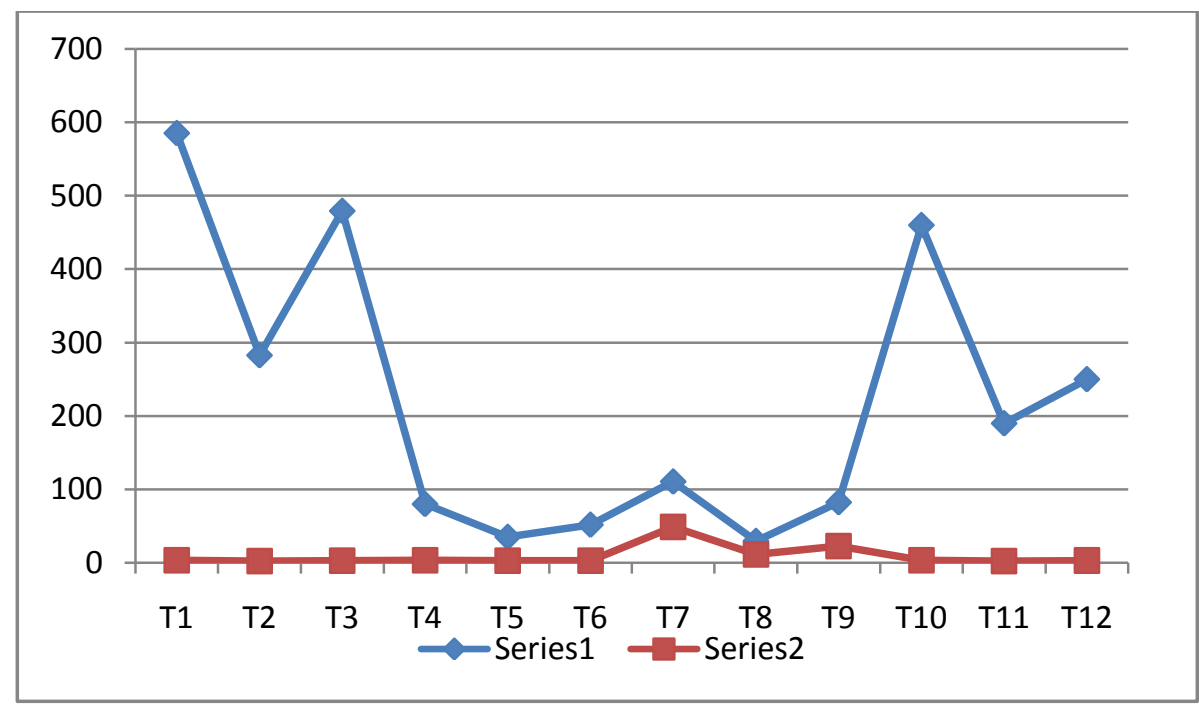

Figure 3. Comparison between soil nitrogen and leachate nitrate content 


\section{CONCLuSiON}

The interaction of fertilizers performed very best in both soil nitrogen content and leaching loss. Among them, combination of poultry manure with recommended level of fertilizer treated soils showed highest soil nitrogen content. But the nitrate leaching rate does not differ among the organic manures. Among the sole application also poultry manure performed best. But in all cases performance of straw was not satisfactory. However with increasing rate of application of fertilizer, the nitrogen content of soil also increases. Therefore by combining poultry manure with chemical fertilizer plant can efficiently utilize the added nutrient and also can reduce nitrate leaching.

\section{REFERENCES}

Amanullah, M., Somasundaram, E., Vaiyapuri, K. and Sathyamoorthi, K. 2007. Poultry manure to crops - A review. Agric. Rev., 28 (3): 216-222.

Ariyaratne, R. M. (2008). Integrated Plant Nutrition Systems (IPNS). Soils of Sri Lanka and Integrated use of organic manures and chemical fertilizers and principles. (Ed. S. T. B. Dissanayake). Training Manual. Department of Agriculture, Peradeniya. Sri Lanka. Pp.22 \& 53-65.

Ayeni L.S. 2008. Integrated Application of Cocoa Pod Ash And NPK Fertilizer on Soil Chemical Properties and Yield of Tomato. American - Eurasian Journal of sustainable Agriculture. 2 (3) 333 - 334

Chen JH. 2006. The combined use of chemical and organic fertilizers and/or biofertilizer for crop growth and soil fertility. Proceedings of International Workshop on Sustained Management of the Soil-Rhizosphere System for Efficient Crop Production and Fertilizer Use. Available fromhttp://www.agnet.org/ htmlarea_file/library/20110808103954/tb174.pdf [Google Scholar]).

FAO, (2000). Manual on integrated soil management and conservation practices. Land and Water bulletin - 8 . Food and Agricultural Organization of the UN, Rome. Pp.10-12.

Gupta, P. K. (1999). Water analysis, Soil, Plant, Water and Fertilizer analysis. Agro Botanica. Pp. 78-84.

Singh, R.A. 2007. Effect of variable doses of potassium, sulphur and calcium on pod yield of short duration summer groundnut (Arachis hypogaea) International J. Agric. Sci., 3 (1): 196-198.

Tao, R., Jingguo W., Qing C., Fusuo Z., and Shuchang L. 2014. The Effects of Manure and Nitrogen Fertilizer Applications on Soil Organic Carbon and Nitrogen in a High-Input Cropping System. PLOs One. 9(5). E 97732. https://www.ncbi.nlm.nih.gov/pmc/articles/PMC4022645/.

Wijewardena, J. D. H. (2006). Improvement of plant nutrient management for better farmer livelihood, food security and environment in Sri Lanka. Proceedings of a Regional Workshop Beijing, China. Food and Agriculture Organization of the United Nations Regional Office for Asia and the Pacific Bangkok, Pp.7393.

Wild, S. A., Corey, R. B., Iyer, J. G and Voigt, G. K. (1997). Analysis of chemical characteristics of soil. Soil and plant analysis for tree culture. Mohan Primlani for oxford and IBH publishing company. PP 45-91.

Citation: P. Premanandarajah, " Selection of Best Combination of Nutrient Sources for Efficient Utilization of Nitrogen in Sandy Regosols ", International Journal of Research in Environmental Science , vol. 3, no. 4, p. 29-32, 2017. http://dx.doi.org/10.20431/2454-9444.0304005

Copyright: (C) 2017 Authors. This is an open-access article distributed under the terms of the Creative Commons Attribution License, which permits unrestricted use, distribution, and reproduction in any medium, provided the original author and source are credited. 